\title{
Study and Characterization of A Novel Multi-Airlift Chemical and Bioreactor
}

\author{
D. Wolf *, A. N. Sembira** \\ *(Department of Chemical Engineering, Ariel University, Ariel, Israel 40700 \\ Email:dwolf@ariel.ac.il) \\ ** (Nuclear Research Centre, P. O. Box 9001, Beer-Sheva, Israel \\ Email: ashersa@nrcn.org.il)
}

\begin{abstract}
This paper presents the results obtained by the R\&D of a multi-channel airlift photobioreactor for growing algae. The work consists of the design, construction, operation and characterization of a multi-channel airlift photobioreactor. Porphyridium Sp, a species of algae of commercial interest was tested. The description of the photobioreactor the experimental set up, and the data obtained in the indoor experiment using artificial solar radiation at the laboratory scale are presented.
\end{abstract}

Keywords: Airlift Photobioreactor, Porphyridium, Marine algae, Polysaccharides, Biomass productivity, CO2 capture, Residence time distributions

\section{INTRODUCTION}

The feasibility of growing algae as a source of proteins or secondary metabolites has been successfully proven by many investigators, and in fact has reached several industrial applications. The potential of growing algae has been discussed in the literature by Kargi and Rosenberg [1], Arad [2], Richmond [3] Bahadar [4] and others. Several methods of large-scale cultivation have been proposed, tested, and implemented. The most common method of cultivation of algae is the openpond raceway method. However, this method has several drawbacks such as contamination caused by other organisms and pollutants as well as a low rate of production due to the unstable operating conditions caused by irradiation, evaporation, temperature fluctuations, and the large land area required for large-scale production. Recently, a closed system was studied by Cohen and Arad [5] where "sleeve"-type photo bioreactors made of polyethylene were used in the growth of the algae Porphyridium Sp.

The sleeve-type operation eliminates many of the disadvantages of the raceway-type photobioreactor and is a good alternative for algae production. Indeed, Arad et al. [6] found that productivity in a closed system was higher than in open ponds. The goal of our research was to test an alternative method, simple and cost-effective for growing algae. The idea is to use a multi-channelairlift photobioreactor that was tested indoors on a laboratory scale. The type of algae tested was Porphyridium $\mathrm{Sp}$, which produces polysaccharides with gelling properties (Arad et al. [6, 8]). This type of reactor produces good mixing conditions and low shear stress. Fermandes et al. [7] lately characterize a slip cylinder airlift photobioreactor for efficient microalgae cultivation.

\section{Algae CUltivation}

The growth of algae in general is affected by factors such as temperature, $\mathrm{pH}$, concentration of nutrients, concentration of $\mathrm{CO} 2$, intensity of irradiation, mixing and shear stress. The production of algae on an industrial and economical basis will therefore depend on optimization of the above parameters. The technology developed for the photobioreactor is also a major influencing factor of production efficiency of the algae and its cost effectiveness. Although the economics at this point is not really favorable for algae production for the biomass alone, it is however economical in some cases where secondary metabolites with higher economic value are produced. Among the algae with industrial potential that have been studied is Porphyridium Sp.

\subsection{Porphyridium Sp}

The potential for producing sulfated polysaccharides from Porphyridium is described by several authors (Arad et al., [8]; Adda et al., [9]; Anderson and Eakin, [10]). From experimental work by Cohen and Arad [5], one can learn about the problems involved in indoor cultivation of Porphyridium, such as low productivity. On the other hand, while growing Porphyridium in polyethylene "sleeves," higher productions of biomass and polysaccharides was achieved. The advantages in the closed system using sleeves are high light availability, high rate of heating and 
cooling, improved mixing, reduced contamination, reduced evaporation, and reduced salinity fluctuations. More details on Porphyridium and outdoor cultivation of algae are given by Goldman [11] and Fuentes-Grunewald [12].

\subsection{Airlift Reactors}

The process of moving material using the airlift principle is quite common in fluid-flow operations. However, in the last 30 years, the airlift principle has also been applied in chemical and biological reaction processes. The airlift-type photobioreactor has gained wide acceptance as an efficient operating unit and is frequently replacing classical stirred tank reactors (STR). The airlift reactor offers good mixing conditions and increased mass transfer for nutrients and gases. The singlechannel airlift reactor commonly studied comprises a riser, a downcomer, a base, and a separator for the gases from the liquid medium. After separation, the gases leave the system while the medium phase comprising biomass and nutrients is recirculated through the downcomer and returns to the riser. Fig. 1 presents an illustration of a typical airlift reactor.

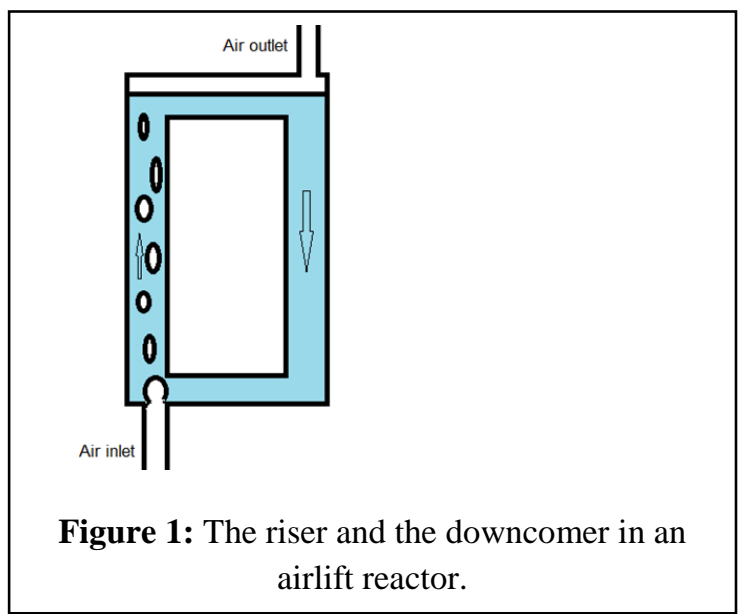

Merchuk and Siegel [13] have reviewed the characteristics of the single-channel airlift bioreactor and its mode of operation. A complete state-of-theart discussion on these reactors as well as existing data on their performance is found in the book by Chisti [14].

\subsection{Objectives and significance}

From an analysis of the need of the photosynthetic processes and the potential of the existing airlift-type bioreactors, we have developed and tested a new type of multi-channel airlift photobioreactor by growing algae of the Porphyridium species. A typical air-lift reactor is shown in fig. 2.



Figure 2: A typical multi-channel airlift photobioreactor.

The objective in the development of this multi-channel airlift photobioreactor was to obtain a more efficient and cost-effective unit operation in the production of algae. This unit operation requires very little energy other than solar radiation. It also uses low-grade water, simple nutrients, and land unsuitable for other agricultural uses.

Even in places where land is relatively expensive, the proposed photobioreactor would utilize land more efficiently due to its vertical growing method, in contrast to horizontal algae cultivation by ponds, thus significantly reducing land requirements. As a closed system, the algae are protected from contamination and the environment is protected from odors. The proposed photobioreactor also can be operated in batch mode, in continuous mode, or in cascade mode. Therefore the R\&D work described here has practical significance in that it could increase the efficiency of algae growth in absolute terms and on a unit land area basis.

\subsection{Extent of illumination}

In the commonly used raceway-type pond, the liquid is approximately $30 \mathrm{~cm}$ deep although solar radiation is absorbed in the first few centimeters of the liquid (Ben Amotz \& Avron, [15]). This is the case because the paddle-wheel type of mixer, usually requires a minimum amount of liquid height in order to obtain good mixing. This means that the ratio of the volume of the liquid in the pond to the irradiation area of the pond is 300 $\mathrm{L} / \mathrm{m}^{2}$. The sleeve-type photoreactor also competes favorably with pond-type reactors, and a sleeve of $10 \mathrm{~cm}$ diameter and $1 \mathrm{~m}$ length has a hold-up of 7.85 $\mathrm{L}$ and an area for irradiation of 0.16 which is 49 $\mathrm{L} / \mathrm{m}^{2}$ of irradiation area. 
The next comparison would be the amount of irradiation that can be obtained from one square meter of land, by the pond-method and by the proposed photobioreactor. Irradiation for one square meter of pond area is, of course, one square meter, and a hold-up of 300 liter. Assuming that we only place two reactors per square meter of land, each two meters high, one meter wide and $5 \mathrm{~cm}$ dip, the irradiation area would be $8 \mathrm{~m}^{2}\left(2 \mathrm{~m}^{2}\right.$ on each side of the reactors), with a liquid holdup of $200 \mathrm{~L}$, which is $25 \mathrm{~L} / \mathrm{m}^{2}$ of irradiated area. Of course different dimensions of our reactor would give different volumes per square meter of irradiation area but yet competitive with the other photoreactors.

\section{DESCRIPTION OF THE MULTI- CHANNEL AIRLIFT PHOTOBIOREACTOR}

The experimental photobioreactor used is of the airlift type with multiple channels and flow loops and a large ratio of irradiation area per medium volume. This multi-channel airlift photobioreactor was constructed of parallel and transparent plastic sheets, connected by partitions at equal distances, forming a honeycomb pattern, as shown in Fig. 3.

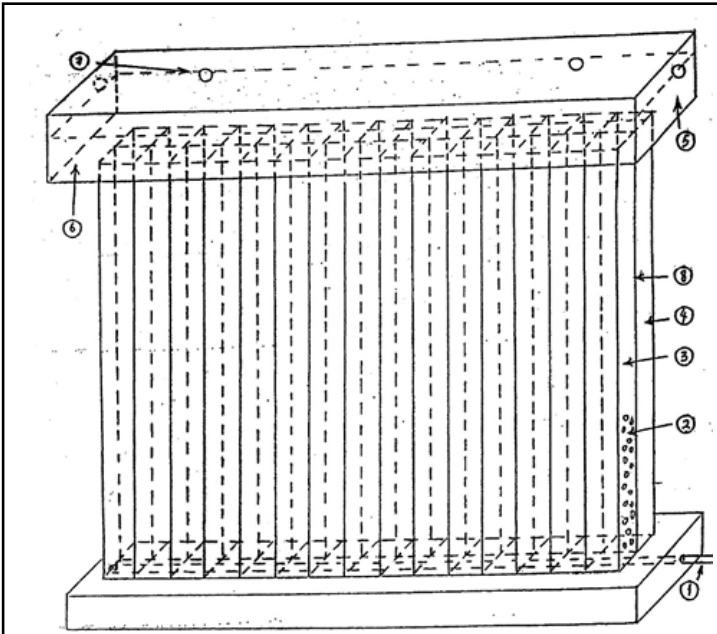

Figure 3: Schematic of the photobioreactor with two rows of channels.

(1) Air inlet enriched with $\mathrm{CO}_{2}$. (2) Gas bubbling in the riser. (3) Riser. (4) Downcomer. (5) Gas separator. (6) Medium nutrients and algae. (7) Gas outlet. (8) Separating plate.

This unit is constructed of three parts: the panel, the base, and the separator. The main part, which is the panel, is commercially available. These panels can be obtained in different shapes and sizes or can be fabricated according to any desired specification.
These were among the incentives to develop such a photobioreactor. Two types of reactors were built and tested. Type A has two parallel plates of transparent plastic with partitions between them and the flow in the risers and downcomers are in the same plane. Type B has three parallel plates with partitions between every two plates so that one can design the risers and downcomers in a variety of ways. The concept of the multi-channel airlift photobioreactor and the types tested is shown schematically in Figure 4.

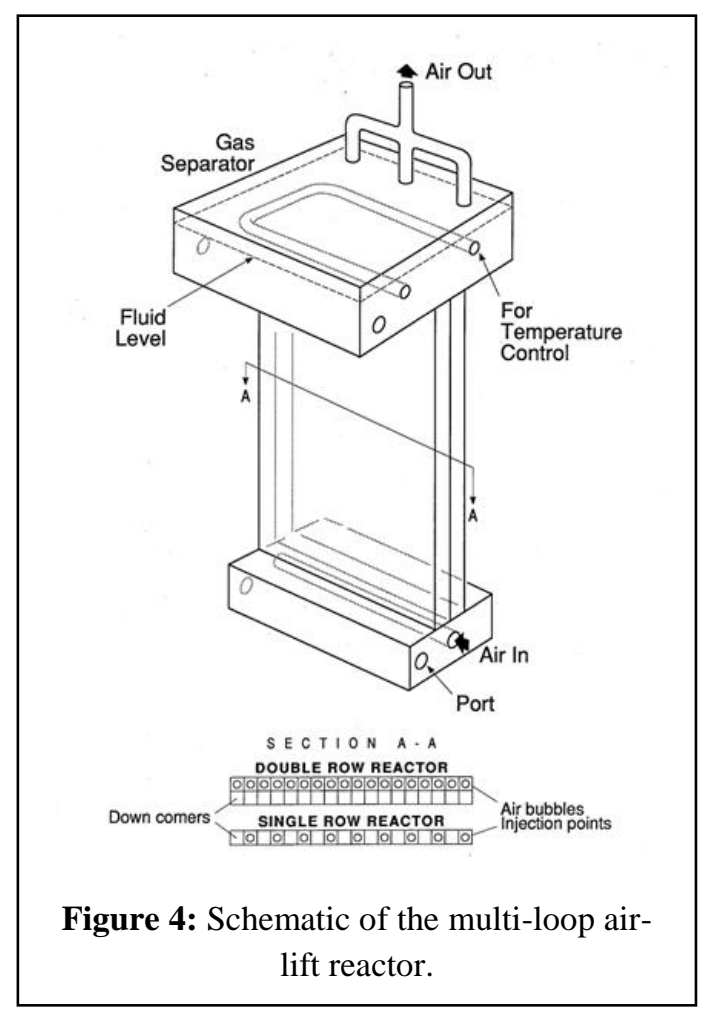

The lower part of the reactor, the base, is a manifold connecting all the channels of the airlift photobioreactor is shown in figure 5 .

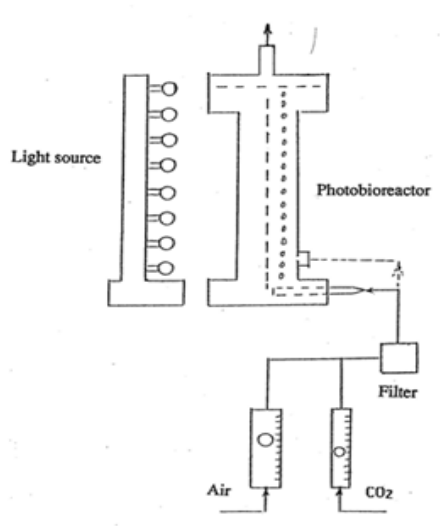

Figure 5: Schematic of the experimental set-up. 
Another "manifold" is the separator, which separates the gases from the liquids or slurries. Perforated pipes inserted in the base i.e. a gas distributor manifold along the lower part of the wall of the reactor serve as air spargers for the airlift risers. The configuration of the holes in the pipes or gas distributor manifold, determines which channels are risers and which are downcomers. The number of holes also determine the ratio of risers to downcomers. The ratio of $1: 1$ that we presently used is not necessarily the optimum condition, and the multi-channel airlift photobioreactor can change this ratio based on the requirements of the mixture and the mass transfer conditions of the system. The height of the photobioreactor can vary and depends on the properties of the fluids used in the reactor. For example, for high viscosities, densities or concentrations of solid particles, the optimum height may be different that for lower viscosities, densities, or concentrations of solid particles. These physical properties may also affect the desired ratio between the number of risers and downcomers in the photobioreactor. Ports for inlet and outlet flow are either at the base, at the separator, or at both ends. Heating and cooling elements can be added for proper temperature control.

The need for temperature control is because in systems that depend on solar radiation, reactions are slower in the morning until the temperature of the medium rises to the proper temperature and irradiation increases. Later in the day, the system may need cooling if the temperatures are too high, or heating when the sun goes down and cooling occurs. Similar reasoning could be when there are season changes. A heat exchanger installed in the separator can supply appropriate temperature control and thus increase production efficiency.

The operation of a multi-channel airlift photobioreactor starts by feeding air first into the reactor at a low flow rate, and then the nutrient medium is slowly added. The liquid in the separator is maintained at a level that minimizes the entrainment of bubbles in the downcomers. The air should pass through a humidifier to avoid excessive evaporation from the reactor by the air stream. Distilled water is added using a liquid level control system that maintains the fluid in the reactor at a constant level. A filter on the air line is used to eliminate dust, microbes and oil droplets from the air. A stream of $\mathrm{CO}_{2}$ is added to the stream of air in order to increase $\mathrm{CO}_{2}$ concentration and thus increase the reaction rate.

In order to use the multi-channel airlift bioreactor for photosynthetic reactions, the reactor should be constructed of transparent materials. Glass would be the obvious choice, but its cost and fragility work in favor of transparent plastic materials. Plastic materials that can be used are all available on the market and have no unfavorable effects on the biological material in the reactor. Also the light transmissivity, or resistivity to UV radiation can be selected on the cost basis only.

\section{Reactor development}

The first stage in this work was the reactor development. Four types of multi-channel airlift photobioreactors were designed, constructed, and installed in our laboratory in order to test the technical feasibility of these types of reactors.

\section{EXPERIMENTAL}

\subsection{Reactor with one row of channels in series -} REC1

REC 1, the first reactor to be tested, had one row of serial-attached channels, that is, all channels were on the same plane, with one riser for every two neighboring downcomers. Reactor dimensions were $40 \mathrm{~cm} \mathrm{~L}$ (length), $35 \mathrm{~cm} \mathrm{H}$ (high), and $0.7 \mathrm{~cm} \mathrm{~W}$ (width). Of the total 57 channels, 19 were risers and 30 were downcomers. Channel dimensions were 0.7 by $0.7 \mathrm{~cm}$. The separator was 5 $\mathrm{cm}$ high, $1.5 \mathrm{~cm}$ wide, and $45 \mathrm{~cm}$ long. The active holdup of this reactor, including the separator, was $830 \mathrm{ml}$.

In the lower manifold, needles were inserted into the risers for gas supply and each needle had a two-way valve, thus enabling the gas flow to strop if the riser was to be changed to a downcomer. This arrangement enabled us to change the ratio of risers and downcomers at will.

However, this type of gas inlet proved to be cumbersome in design and operation, and was not justified at this stage of the research and development. Therefore, a second type of reactor was designed and constructed.

\subsection{Reactor with two rows of serial-attached channels - REC2}

The second reactor tested, REC2, was constructed of two rows of serial-attached channels, as shown in Figure 3. This reactor, which was $47 \mathrm{~cm}$ long, had two rows of 23 channels each. The dimensions of each channel were 0.7 by $2.0 \mathrm{~cm}$. The height of the reactor was $48.0 \mathrm{~cm}$. In the lower manifold there was a stainless steel perforated pipe beneath the row of channels that were risers. The second row of channels was designated as the downcomers. The gas separator was $12 \mathrm{~cm}$ high, 5.3 $\mathrm{cm}$ wide, and $57 \mathrm{~cm}$ long. Normally, the liquid level in the separator was approximately $6 \mathrm{~cm}$. The total liquid holdup under normal operating conditions was $4 \mathrm{~L}$.

\subsection{Reactor with two rows of serial-attached channels - REC3}

A third reactor, REC3, was constructed with the same structure as REC2 but was $48.0 \mathrm{~cm}$ long, 67 
$\mathrm{cm}$ high, and had two rows of 24 channels each. The separator was $12.5 \mathrm{~cm}$ high, $8 \mathrm{~cm}$ wide, and 59 $\mathrm{cm}$ long. These changes made the holdup of the reactor at operating conditions to be $8 \mathrm{~L}$.

REC3 also had a perforated pipe for the air flow into the risers but it was made of PVC. Due to the flexibility of the pipe, it was not stable and was replaced by a stainless steel pipe.

\subsection{Reactor with two rows of serial-attached channels - REC4}

After gaining experience with the three previously described reactors, an improved type of reactor, REC4, was constructed and finally adopted for this R\&D work. The channels have the same dimensions as REC2 and REC3. The width of the reactor is $48.8 \mathrm{~cm}$, the height is $57 \mathrm{~cm}$, with 24 channels per row. The separator is $13 \mathrm{~cm}$ high, 65 $\mathrm{cm}$ long, and $9.7 \mathrm{~cm}$ wide. The main modification in this reactor was the air inlet system. A manifold was attached on the side of the channels designated as risers, approximately $10 \mathrm{~cm}$ from the bottom, and small holes were drilled into the wall of the risers. This type of air supply system proved to be simpler in construction and more reliable in operation. This type of system is schematically shown in Figure 4.

\subsection{Light sources}

Three types of light sources of varying density and number of bulbs were prepared. The first light source, Sun 1, was constructed of 4 bulbs and was suitable for REC1 and REC2. The bulbs were Osram daylight-type cool-white fluorescent lamps and were $20 \mathrm{~W}$ each. The second light source, Sun 2 , was constructed of 8 bulbs and was suitable for all the reactors, and had the same light intensity per unit area as Sun 1. The third light source built so far was Sun 3, which was constructed of 16 bulbs and thus the light intensity was per unit area of light source. The bulbs were of the same type as those used in Sun 1 and Sun 2.

\subsection{Shake-down experiments}

In the shake-down operation stage, several experiments were conducted to test the operability of the multi-channel airlift system and its ability to serve as a photobioreactor in the process of growing algae. In the shake-down stage, all experiments involved growing Porphyridium in an artificial seawater medium. Air was supplied to the system using a rotameter with a maximum flow rate of 136 $\mathrm{cc} / \mathrm{min}$.

In these preliminary experiments, we used reactor REC1 and light source Sun 1. The experiments were conducted without the addition of $\mathrm{CO}_{2}$ and thus $\mathrm{pH}$ increased from around 7 to around 9 , except when contamination occurred and $\mathrm{pH}$ decreased to around 6.0. The experiments were frequently terminated due to various technical issues.

An appropriate flow rate of air had to be found so that the algae would not settle due to a low flow rate of air and prevent excessive foaming caused by a large flow rate of air.

Even during these preliminary experiments, significant growth of algae was obtained as well as polysaccharide production. The dissolved polysaccharide was between $0.4-0.6 \mathrm{mg} / \mathrm{ml}$, with a production rate of $0.05 \mathrm{mg} / \mathrm{ml}$ per day. However, contamination was also encountered in several experiments, and the significance of sterile operating conditions was determined. Sterilization was achieved by circulating a mixture of 70 wt. \% alcohol and 30 wt. \% water through the system for about 24 hours, and then rinsing three times with distilled and sterilized water.

These experiments, with low light intensity and no addition of $\mathrm{CO}_{2}$, already demonstrated the potential of this type of reactor. However, since the effect of increased light intensity on the growth of algae and polysaccharides is very significant, another set of experiments were conducted with high light intensity and addition and $\mathrm{CO}_{2}$. Reactor REC2 was constructed and used in this new series of experiments. A rotameter with a maximum flow rate of $21 \mathrm{ml} / \mathrm{min}$ was also used to control the $\mathrm{CO}_{2}$ flow rate. During the winter season, a heating element was inserted into the separator to control the temperature at $25^{\circ} \mathrm{C}$. Porphyridium $\mathrm{Sp}$. with artificial sea water (ASW) was used once again as the medium, and prepared according to Jones et al. [16].

Before any experimental run, the reactor was cleaned and then filled with ASW to the appropriate level to allow the addition of inoculum before the final level in the separator was achieved. Daily measurements of temperature, $\mathrm{pH}$, light transparency, and cell counts were performed. The initial cell concentration was prepared in the range of $2-3 \times 10^{6}$ cells $/ \mathrm{ml}$. Samples were also taken to determine the polysaccharides in the medium and the cells.

The results of the shake-down experiments proved the operability of the reactor, but several problems emerged and required solutions. As the production of the polysaccharides started, especially in the stationary stage, foaming occurred in the system. Addition of an antifoam reduced foaming but also reduced the growth rate of the algae. Several technical modifications were introduced in the exit lines of the gas to prevent overflow of the foam and the cells that were carried with the foam.

Sterile operating conditions were needed as contamination was quite common. Several shakedown runs were successful, and at their conclusion we were ready to operate the reactor with confidence. Cell concentration of $5 \times 10^{7}$ cells $/ \mathrm{ml}$ or 
higher was achieved when the stationary phase was reached. Addition of 200-300 ml of distilled water per 24 hours was also required due to evaporation. It was found that a good correlation exists between the light transparency through the reactor and the cell concentration in the reactor.

\subsection{Experimental work}

The reactors, its auxiliaries, and control units were tested for proper operating conditions until good operability was achieved. A diagram of the experimental set-up was shown in Fig. 4. The experiments were conducted with (a) Porphyridium Sp. of type UTEX 637 [8]. Periodic tests were conducted on the biomass, the secondary metabolites, and the conditions of the nutrients.

The experimental work consisted in growing algae in the photobioreactor and analyzing the results. Cell counts were performed daily for the algae in order to obtain the growth rate in this reactor. Polysaccharides in the cells and in the medium were analyzed. Light transmission through the reactor walls were measured daily on the wall opposite the light source. A Li-Cor light meter type Li-170 with $\mathrm{Li}-200 \mathrm{~S}$ probe was used to measure light intensity.

Operating conditions were monitored and recorded. Data were taken under various operating conditions. Distilled water was always added to make up for evaporation losses.

All experiments reported here were conducted in the laboratory with artificial light supplied continuously, 24 hours a day.

Experiments with Porphyridium Sp. were conducted in both, batch mode and continuous mode. The inoculum of the Porphyridium into the photobioreactor, which was prepared in a $300 \mathrm{ml}$ glass column of $6 \mathrm{~cm}$ in diameter, was calculated so that the initial concentration was $2-4 \times 10^{6}$ cells $/ \mathrm{ml}$. As noted above, the medium was ASE, prepared according to Jones et al. [16]. Details on the preparation of the medium and the analytical procedures were obtained from Arad [17]. In each case we added $\mathrm{CO}_{2}$ to the stream of air supplied to the photobioreactor.

The cells were counted everyday using a microscope. The stationary phase was achieved in approximately 6 days. The quantity of polysaccharides in cell walls and in the medium was obtained using the method described by Adda et al. [8]. Nitrate starvation affects the distribution of polysaccharides between that which is bound to the cell and that of the soluble fractions. Light intensity was also measured. Finally, the amount of biomass was determined.

\subsection{Batch experiments}

Two experiments were conducted in a batch operating mode.

Cell counts and light transparencies of Experiment 1 are given in Table 1. Light transparency was measured as the light intensity on the plane opposite to the plane where the light impinged on the reactor. One bank of 8 lamps was used as the light source (Sun 2). The experiment lasted 9 days and the maximum number of cells obtained after 7 days was $60.8 \times 106$ cells $/ \mathrm{ml}$. Temperatures during the experiment fluctuated between $21.5^{\circ} \mathrm{C}$ to $26.5^{\circ} \mathrm{C}$, which is indeed the range of its optimum temperatures [18] and $\mathrm{pH}$ ranged from 6.8 to 7.9. A pH of 7.5 is considered to be the optimum condition. The analytical results of the sugars in the cells and in the medium are given in Table 1

Table 1: Results of Experiment 1: Batch-mode Porphyridium growth

\begin{tabular}{|c|c|c|c|c|}
\hline \multirow{3}{*}{$\begin{array}{l}\begin{array}{l}\text { No. of } \\
\text { days }\end{array} \\
1\end{array}$} & \multirow{3}{*}{$\begin{array}{l}\text { Counts } \\
\text { of algae } \\
\times \mathbf{1 0}^{\mathbf{6}} \\
3.6\end{array}$} & \multirow{3}{*}{$\begin{array}{l}\text { Light } \\
\text { intensity* } \\
\text { Watts/m² } \\
30.4\end{array}$} & \multicolumn{2}{|c|}{$\begin{array}{l}\text { Polysaccharides } \\
\mathrm{mg} / \mathrm{L}\end{array}$} \\
\hline & & & $\begin{array}{l}\text { In } \\
\text { medi }\end{array}$ & In cells \\
\hline & & & - & - \\
\hline 2 & 6.3 & 23.2 & - & - \\
\hline 3 & 10.2 & 10.4 & 0.16 & 0.30 \\
\hline 4 & 24.2 & 2.0 & - & - \\
\hline 5 & 38.2 & 4.0 & 0.16 & 0.90 \\
\hline 6 & - & - & - & - \\
\hline 7 & 60.8 & 2.2 & 0.27 & 1.55 \\
\hline 8 & 58.9 & 2.2 & - & - \\
\hline 9 & 50.9 & 2.4 & 0.35 & 2.49 \\
\hline \multicolumn{5}{|c|}{$\begin{array}{l}\text { *Light intensity was measured at the wall of the } \\
\text { reactor opposite to the plane to which light was } \\
\text { applied. One bank of } 8 \text {, aps was used. Temperatures } \\
\text { ranged between } 21.5^{\circ} \mathrm{C} \text { and } 26.5^{\circ} \mathrm{C} \text {, and pH ranged } \\
\text { between } 6.8 \text { to } 7.9 . \mathrm{CO}_{2} \text { was added to the gas } \\
\text { stream. The volume of the reactor was } 7 \mathrm{~L} \text {. }\end{array}$} \\
\hline
\end{tabular}

The second experiment (No. 2) was conducted with a double bank of irradiation lamps (Sun 2), one on each side of the reactor. In all other respects, operating conditions were identical to those in Experiment 1 . Temperatures ranged between $21.5^{\circ} \mathrm{C}$ and $27.0^{\circ} \mathrm{C}$, and $\mathrm{pH}$ ranged between 6.9 to 7.6. The results are summarized in Table 2 . 


\begin{tabular}{|lllll|}
\hline \multicolumn{5}{|c|}{ Table 2: Results of Experiment 2: Batch-mode } \\
Porphyridium growth.
\end{tabular}

\subsection{Continuous mode}

\subsection{Continuous mode}

Three experiments were conducted in a continuous operating mode. Experiment 3 was conducted with a double bank of light (Sun 2) and in a continuous mode. In this mode a certain amount of medium and the cells it contained was removed, daily and fresh medium was added to the reactor. Temperatures ranged between $24.0^{\circ} \mathrm{C}$ and $29.0^{\circ} \mathrm{C}$, and $\mathrm{pH}$ ranged between 6.7 to 7.3 .The results obtained are summarized in Table 3.

It is evident that a very high concentration of cells was achieved for quite some time. However, polysaccharide concentrations were much lower than those obtained in the batch-mode experiments.

Experiment 4 was conducted with the same operating conditions as experiment 3 , with the exception of only using one bank of lights with double intensity (Sun 3). Temperatures ranged between $23.0^{\circ} \mathrm{C}$ and $29.5^{\circ} \mathrm{C}$, and $\mathrm{pH}$ ranged between 7.1 to 7.5. Results are summarized in Table 4.

Experiment 5 was conducted using regular light (Sun 2). Temperatures ranged between $21.0^{\circ} \mathrm{C}$ and $28.5^{\circ} \mathrm{C}$, and $\mathrm{pH}$ ranged from 6.5 to 7.4 . Results are given in Table 5.

\section{MIXING AND GAS HOLDUP}

Mixing conditions and gas holdup for REC1 were studied. The mixing aspect involved flow rates in the downcomers, and time of dispersion in the reactor. Flow rates were obtained by measuring the time required for a small plastic ball to pass through the downcomer. Dispersion time was obtained by measuring light transparency at three sites on the reactor wall between the injection of a colored tracer and until a constant reading was obtained. Liquid velocity in the downcomer was found to be in the range of $10-20 \mathrm{~cm} / \mathrm{sec}$ for a superficial gas velocity in the riser between 30 and $300 \mathrm{~cm} / \mathrm{sec}$.

An approximate equation for the superficial gas velocity $\mathrm{V}_{\mathrm{sa}}$ in the riser and the liquid velocity in the downcomer $\mathrm{V}_{\mathrm{dl}}$ is:

$\mathrm{V}_{\mathrm{dl}}=3.36 \times \mathrm{V}_{\mathrm{sa}} 0.315$

Typical example of the dispersion time can be seen in Fig. 6.

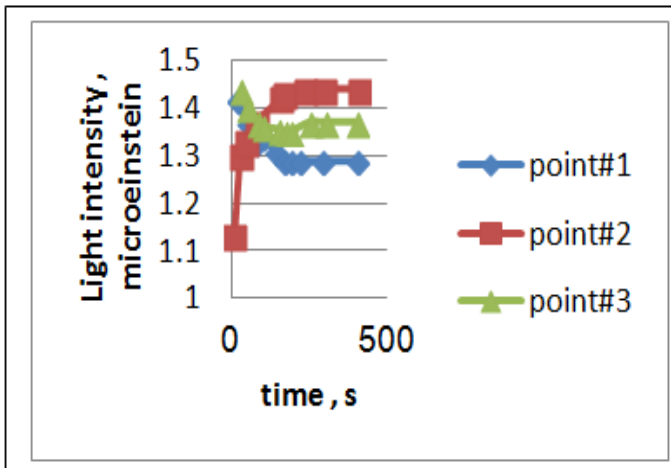

Figure 6: Dispersion as function of time in reactor Rec1.

After approximately $250 \mathrm{sec}$, the system was uniform and light transmission at all sites was constant. Light transmission at these sites differed because the basic transmission at each differed due to non-uniformity of the material of the reactor's construction. Dispersion time is a function of the superficial gas velocity in the riser Vsa and it drops as Vsa increases, as shown in Figure 7.

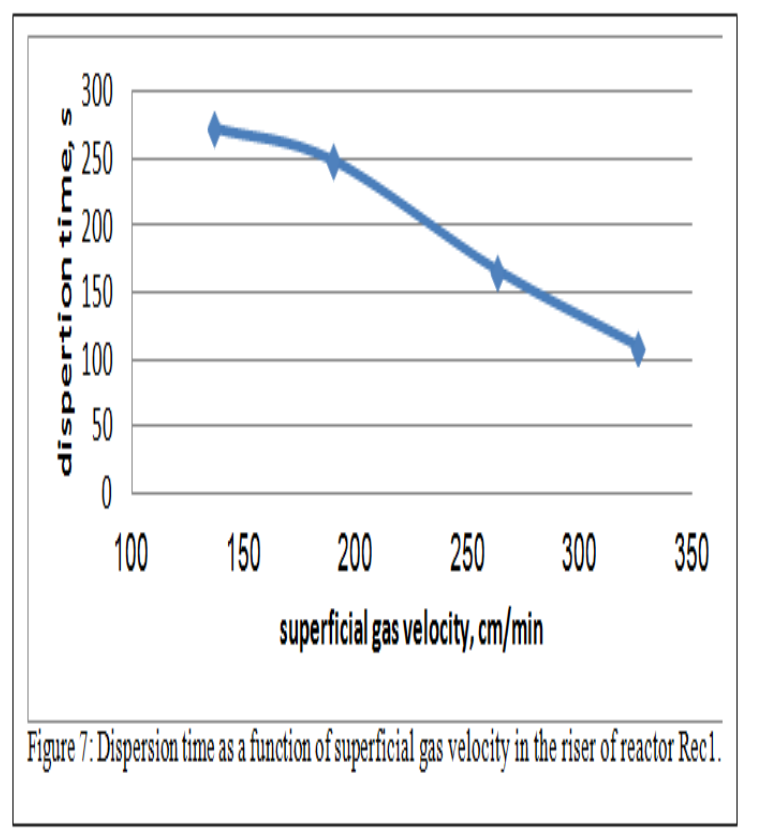


Table 3: Results of Experiment 3: Continuous-mode Porphyridium growth

\begin{tabular}{|c|c|c|c|c|c|c|}
\hline \multirow[t]{2}{*}{ No. of days } & \multicolumn{2}{|c|}{ Counts of algae $\times 10^{6}$} & \multirow{2}{*}{$\begin{array}{l}\text { Medium } \\
\text { changed, L. }\end{array}$} & Light intensity* Watts $/ \mathrm{m}^{2}$ & \multicolumn{2}{|c|}{ Polysaccharides mg/L } \\
\hline & $\begin{array}{l}\text { Before product } \\
\text { taken }\end{array}$ & $\begin{array}{l}\text { After product } \\
\text { taken }\end{array}$ & & & In medium & In cells \\
\hline 2 & 4.0 & & & 58.0 & 0.13 & 0.26 \\
\hline 3 & 17.2 & & & 25.0 & - & - \\
\hline 6 & 75.6 & 56.1 & 2 & 5.0 & 0.13 & 0.28 \\
\hline 7 & - & - & - & - & - & - \\
\hline 8 & 135.8 & 102.4 & $1+0.80 *$ & 4.8 & 0.26 & 0.54 \\
\hline 9 & 132.2 & 97.7 & $1+0.20$ & 6.4 & 0.26 & 0.54 \\
\hline 10 & 154.4 & 100.2 & $1+0.60$ & 8.6 & 0.27 & 0.55 \\
\hline 14 & - & - & - & - & - & - \\
\hline 15 & 125.0 & 104.1 & $1+0.20$ & 6.4 & 0.26 & 0.54 \\
\hline 16 & 105.5 & 67.9 & $1+0.350$ & 5.8 & 0.26 & 0.54 \\
\hline 17 & 123.5 & 69.4 & $1+0.20$ & 5.8 & 0.26 & 0.54 \\
\hline 18 & 89.8 & 63.6 & $2+0.10$ & 8.0 & 0.26 & 0.53 \\
\hline
\end{tabular}

\begin{tabular}{|c|c|c|c|c|c|c|}
\hline \multicolumn{7}{|c|}{ Table 4: Results of Experiment 4: Continuous-mode Porphyridium growth } \\
\hline \multirow[t]{2}{*}{ No. of days } & \multicolumn{2}{|c|}{ Counts of algae $\times 10^{6}$} & \multirow{2}{*}{$\begin{array}{l}\text { Medium } \\
\text { changed, L. }\end{array}$} & \multirow[t]{2}{*}{ Light intensity* Watts/m² } & \multicolumn{2}{|c|}{ Polysaccharides mg/L } \\
\hline & $\begin{array}{l}\text { Before product } \\
\text { taken }\end{array}$ & $\begin{array}{l}\text { After product } \\
\text { taken }\end{array}$ & & & In medium & In cells \\
\hline 1 & 1.8 & - & - & 82.0 & - & - \\
\hline 2 & 13.0 & - & $0.60 * *$ & 56.0 & 0.11 & 0.54 \\
\hline 3 & 19.6 & - & 0.90 & 44.0 & - & - \\
\hline 4 & 14.8 & - & 0.70 & 40.0 & 0.24 & 0.86 \\
\hline 5 & - & - & - & - & - & - \\
\hline 6 & 44.8 & - & 0.90 & 12.8 & 0.23 & 1.00 \\
\hline 7 & 32.2 & - & 0.90 & 11.2 & - & - \\
\hline 8 & 30.0 & - & 0.45 & 10.0 & 0.30 & 1.88 \\
\hline 9 & 35.8 & - & 0.60 & 9.6 & 0.31 & 2.11 \\
\hline 10 & 32.7 & - & 0.40 & 7.0 & - & -2.88 \\
\hline 11 & 51.7 & - & 0.20 & 5.4 & 0.93 & 3.34 \\
\hline 12 & - & - & - & - & - & - \\
\hline 13 & 66.6 & 43.6 & $2+0.88$ & 11.8 & 1.43 & 5.50 \\
\hline
\end{tabular}




\begin{tabular}{|c|c|c|c|c|c|c|c|}
\hline \multirow{3}{*}{$\begin{array}{l}\begin{array}{l}\text { No. of } \\
\text { days }\end{array} \\
1\end{array}$} & \multicolumn{2}{|c|}{ Counts of algae $\times 10^{6}$} & \multirow{2}{*}{$\begin{array}{l}\text { Medium } \\
\text { changed, } \\
\text { L. }\end{array}$} & \multirow{2}{*}{$\begin{array}{l}\text { Light intensity* } \\
\text { Watts/m² }\end{array}$} & & \multicolumn{2}{|c|}{ Polysaccharides mg/L } \\
\hline & $\begin{array}{l}\text { Before } \\
\text { product } \\
\text { taken }\end{array}$ & $\begin{array}{l}\text { After } \\
\text { product } \\
\text { taken }\end{array}$ & & & & In medium & In cells \\
\hline & 1.5 & - & - & 80.0 & - & - & - \\
\hline 2 & 1.4 & - & - & 76.0 & - & - & - \\
\hline 3 & 12.1 & - & 0.70 & 52.0 & - & 0.15 & 0.57 \\
\hline 4 & - & - & & & - & & \\
\hline 5 & 60.4 & - & 0.55 & 8.2 & - & 0.16 & 1.06 \\
\hline 6 & 61.9 & - & 1.00 & 7.0 & - & & \\
\hline 7 & 41.0 & - & 0.55 & 7.2 & - & 0.27 & 2.6 \\
\hline 8 & 48.0 & 28.8 & $2+0$ & 7.2 & 10.2 & - & - \\
\hline 9 & 84.7 & 54.4 & $2+0.55$ & 8.0 & 10.6 & 1.14 & 3.09 \\
\hline 10 & 99.4 & 44.3 & $2+0.70$ & 7.2 & 11.2 & 1.01 & 4.53 \\
\hline 11 & - & - & - & - & - & - & - \\
\hline 12 & 114.4 & 105.4 & $2+0.45$ & 6.4 & 10.0 & 1.08 & 3.15 \\
\hline 13 & 116.0 & 102.2 & $2+0.40$ & 6.4 & 7.0 & 1.32 & 2.77 \\
\hline 14 & 100.4 & 40.4 & $2+0.55$ & 7.6 & 10.4 & 1.16 & 2.55 \\
\hline 15 & 85.4 & 63.7 & $3+0$ & 6.4 & 10.2 & 0.81 & 2.15 \\
\hline 16 & 68.6 & - & 0.60 & 6.6 & - & 0.82 & 1.81 \\
\hline 17 & 76.9 & 39.0 & $3+0.30$ & 5.2 & 8.0 & 1.07 & 2.62 \\
\hline 18 & - & - & - & - & - & - & - \\
\hline 19 & 129.2 & - & - & 6.0 & - & 1.03 & 2.71 \\
\hline \multicolumn{8}{|c|}{$\begin{array}{l}\text { * Regular light } \\
* * \text { Amount of distilled water added to make up for evaporation losses. } \\
\text { Temperatures ranged between } 23-29^{\circ} \mathrm{C}\end{array}$} \\
\hline
\end{tabular}

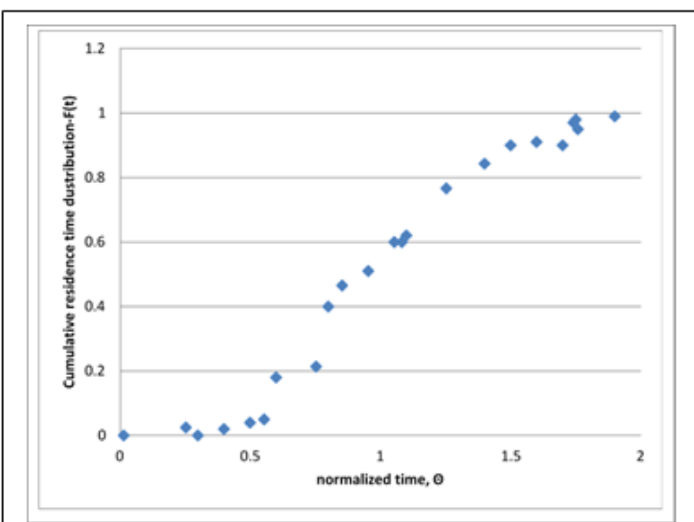

Figure 8: Cumulative residence time distribution in reactor Rec1 for the continuous mode operation.

An analysis of the results using the Wolf and Resnick model [19] shows a significant lag in the response with $\varepsilon=0.5$ and $\eta=1.5$. The flow rates in the downcomer are not different in batch mode and continuous mode operation. The holdup of gas in the reactor was measured by a step change in the gas supply and by measuring the difference in the liquid level with and without the flow of air. The holdup as a function of superficial gas velocity is seen in Figure 9.

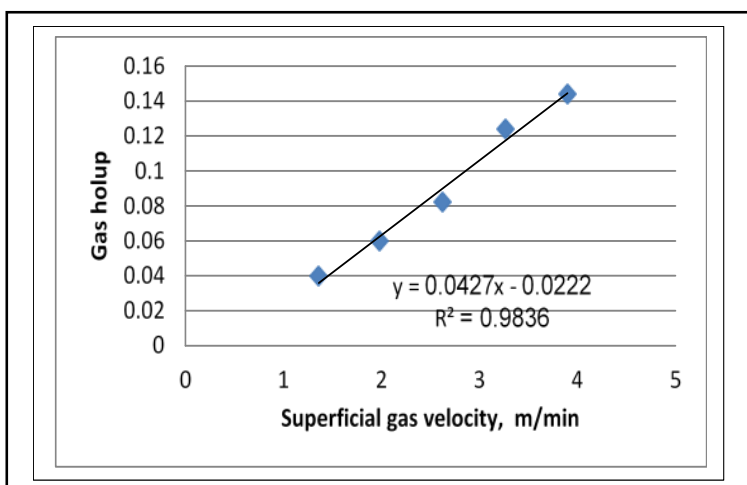

Figure 9: Gas holdup as a function of superficial gas velocity in reactor Rec1. 


\section{CONCLUSIONS}

The multi-channel airlift reactor that we described and tested proved its applicability as an efficient photobioreactor. Therefore future studies are warranted on reactor performance and optimization of the reactor design, on such aspects as dimensions of channels and the reactor itself, number of risers and downcomers, gas flow rates, and liquid recirculation rates. Several problems remain to be resolved such as the frequent contamination of the Porphyridium and foam formation when polysaccharides are produced.

To obtain engineering specifications for the design, the scale-up, and the economic analysis of such a unit operation, the system should be tested outdoors, in real operating conditions of solar radiation, normal and controlled weather conditions, and on a pilot scale. This type of photobioreactor is attractive and industrially promising in view of its good mixing, enhanced mass transfer of $\mathrm{CO}_{2}$ into the liquid, efficient removal of excess oxygen produced during photosynthesis, low shear rates achieved with the airlift principle, high efficiency of radiation absorption due to the narrow channels in the photobioreactor, the high ratio of exposed surface area to reactor volume, and the advantages of a closed system.

\section{ACKNOWLEDGEMENTS}

We express our sincere thanks to the Ministry of Science for the financial support of this R\&D project. We also wish to thank Engineers $S$. Glazer and Z. Ben Shaul for in performing the experimental work. The assistance of the students, M. Zedaka, A. Avigdor, E. Eshel and I Danon is greatly appreciated. Special thanks are extended to Prof. S. Arad and Prof, J. Merchuk.

\section{REFERENCES}

[1]. F. Kargi, \& M. Z. Rosenberg, Plant cell bioreactors: Present status and future trends. Biotechnology Progress, 3, 1987, 1-8.

[2]. S. Arad (Malis), Biochemical from unicellular red algae. International Industrial Biotechnology, June-July, 1987, 281-284.

[3]. A. Richmond, A prerequisite for industrial microalgae culture efficient utilization of solar irradiance. In T. Stadler, J.C., Mollion, M. Verdus, Y. Karamoanos, H. Morvan and D. Christain (Eds.), Algal Biotechnology Essex UK (Elsevier Applied Science 1988).

[4]. M. Ali Bahadar, Bilal Khan Progress in energy from microalgae: A review, Renewable and Sustainable Energy Review, 27, 2013, 128-140.

[5]. M. Y. Cohen, \& S. Arad (MAlis), A closed system for outdoor alga cultivation. Presented at the International Conference of the Society of Applied Algology, Jan 28-Feb 2, 1989, Tiberias, Israel.

[6]. S. Arad, (Malis), O. Freidman (Dahan), \& A. Rorem, Effect of nitrogen on polysaccharide production in a Porphyridium Sp. Applied and Environmental Microbiology, 54,1988, 24112411.

[7]. B. Fermandes , A. Mota, A. Ferreira, G. Dragone, J. A. Teixeira, A. A. Vicente, Characterization a slip cylinder airlift photobioreactor for efficient microalgae cultivation, Chem. Eng. Sci. 117,2014, 445454.

[8]. S. Arad (Malis), M. Adda, \& D. Cohen, The potential of production of sulfated polysaccharides from Porphyridium. Plant and Soil, 89, 1985, 117-127.

[9]. M. Adda, J.C. Merchuk, \& S. Arad (Malis), Effects of nitrate on growth and production of cell-wall polysaccharide by the unicellular red alga Porphyridium. Biomass, 10, 1986, 13140.

[10]. D. B. Anderson, \&D. E. Eakin, A process for the production of polysaccharides from microalgae. Biotechnology and Bioengineering Symposium, 5, 1985, 533-547.

[11]. J. C. Goldman, Outdoor alga mass cultures I. Applications. Water Research, 13(1) '(1979).

[12]. C. Fuentes-Grunewald, C. Bayliss, M. Zanain, C. Pooley, M. Scolamacchia, A. Silkina, Evaluation of batch and semi continuous culture of Porphyridium purpureum in a photobioreactor in high latitudes using Fourier Transform Infrared spectroscopy for monitoring biomass composition and metabolites production, Bioresource Technology 189, 2015, 357-363.

[13]. J. C. Merchuk, M. H. Siegel, Air-life reactors in chemical and biological technology. Journal of Chemical Technology \& Biotechnology, 41, 1988, 105-120.

[14]. M. Y. Chisti, Air-lift reactor (New York: Elsevier 1989).

[15]. A. Ben-Amotz, \& M. Avron, The biotechnology of mass culturing Dunaliella for products of commercial interest. In R.C.Cresswell, T.A.V. Rees and N. Shah (Eds.), Algal and Cyanobacterial Biotechnology (pp. 90-114). (Longman Scientific and Technical Press, London 1989).

[16]. R. F. Jones, H. L. Speer, \& W. Kury, Studies on the growth of the red algae Porphyridium Cruentum. Physiologia Plantarum, 16, 1963 , 636. 
[17]. S. Arad (Malis), Personal communication 1990

[18]. A. Vonshak, Porphyridium. In M.A. Borowitzka and L.J. Borowitzka (Eds.), Micro Algal Biotechnology (pp. 122-134). (Cambridge, UK: Cambridge University Press 1988).

[19]. D. Wolf, \& W. Resnick, Residence time distribution in Real System, Industrial and Engineering Chemistry Fundamentals, 2,1967, 287. 